\title{
Stability Analysis of Wang's Stretching/ Shrinking Sheet Problem for Nanofluids
}

\author{
Mohamad Mustaqim Junoh ${ }^{1, *}$, Fadzilah Md Ali ${ }^{1,2}$, Norihan Md Arifin ${ }^{1,2}$, Norfifah Bachok ${ }^{1,2}$ \\ ${ }^{1}$ Institute for Mathematical Research, Universiti Putra Malaysia, 43400 UPM Serdang, Selangor, Malaysia \\ ${ }^{2}$ Department of Mathematics, Faculty of Science, Universiti Putra Malaysia, 43400 UPM Serdang, Selangor, Malaysia \\ *Corresponding Author: mohamadmustaqimjunoh@gmail.com
}

Received July 11, 2019; Revised August 25, 2019; Accepted September 02, 2019

Copyright (C) 2019 by authors, all rights reserved. Authors agree that this article remains permanently open access under the terms of the Creative Commons Attribution License 4.0 International License

\begin{abstract}
The steady stagnation-point flow of nanofluid over a stretching or shrinking sheet in its own plane is investigated. The governing nonlinear partial differential equations are transformed into a nonlinear ordinary differential equations via the similarity transformation before they are solved numerically using the bvp4c solver in the MATLAB. Three different types of nanoparticles $\left(\mathrm{Cu}, \mathrm{Al}_{2} \mathrm{O}_{3}, \mathrm{TiO}_{2}\right)$ in the water-based fluid are analyzed in this paper. Effects of the solid volume fraction $\phi$ on the fluid flow and heat transfer are evaluated. Numerical results are obtained for velocity and temperature distribution, as well as the skin friction coefficient $f^{\prime \prime}(0)$ and local Nusselt number $-\theta^{\prime}(0)$ are presented graphically. There exist dual solutions for a certain range of stretching/shrinking parameter $\epsilon$. Therefore, a stability analysis is performed to determine which solution is linearly stable and physically realizable. From the stability analysis it is found that the first solution is stable whilst the second solution is not.
\end{abstract}

Keywords Boundary Layer, Dual Solutions, Stagnationpoint Flow, Nanoparticles, Stability Analysis

\section{Introduction}

The number of researchers that discover and examine the fluid flow and heat transfer over a stretching or shrinking sheet problem has been tremendously expended in recent years. The increase in number of researches in this field has been encouraged by the large diversity of real-world applications especially in engineering procedures and productions. In the theory of fluid dynamics, stagnation point flow is the fluid motion near the stagnation region where it exists at the surface of objects in the flow. Hiemenz [1] was the pioneer in stagnation point flow problem. He used a similarity transformation to reduce the Navier-Stokes equations to a nonlinear ordinary differential equation, solving the two-dimensional stagnation flow towards a stationary plate problem. Miklavčič and Wang [2] were the first investigated the flow due to a shrinking sheet. They reported that the boundary layer flow over a shrinking sheet is presence in two conditions which are imposing an adequate suction on the boundary and by considering stagnation flow. On the other hand, the combination of both stagnation point flow and shrinking sheet was considered by Wang [3]. $\mathrm{He}$ found that the shrinking sheet has many unique characteristics such as for a larger shrinking rates, the solution does not exist. Therefore, the study of fluid flow over a stretching/shrinking sheet has been explored by a substantial amount of researchers under different physical conditions. Recently, pioneering efforts on the flow over a stagnation point towards a stretching/shrinking sheet from the past researchers have spark interest to many new researchers. This present study has set a purpose to investigate the effects of nanoparticle volume fraction and the heat integration of nanofluids towards stretching/shrinking sheet. This present work is remotely extending the past work done by Ali et al. [4]. Prior to the work, Ali et al. [4] had done a study on the steady stagnation-point flow of a viscous and incompressible fluid over a continuously stretching or shrinking sheet in its own plane in a water-based copper $\mathrm{C}(\mathrm{C})$ nanofluid using shooting method technique. Solving this problem has resulted in dual-solutions. Therefore, a stability analysis is carried out to determine either the first or second solution is practically acceptable. The stability analysis in this study is done by following the works of [5-9].

\section{Mathematical Formulation}

Take into consideration the steady stagnation-point flow of viscous and incompressible fluid over a stretching or shrinking sheet in its own plane in nanofluid. Following Ali et al. [4] and a model proposed by Tiwari and Das [10], it is presumed that the free stream velocity is $u_{e}(x)=a x$, while the velocity of the stretching sheet is $u_{w}(x)=b(x+c)$, where $a$ is a positive constant, $b>0$ is the stretching rate and $b<0$ is the shrinking rate and $-c$ is the location of the stretching origin. The $x-$ axis is measured along the stretching surface and $y-$ 
axis is perpendicular to it. Under these presumptions, the basic equations of this problem can be derived as follows:

$$
\begin{gathered}
\frac{\partial u}{\partial x}+\frac{\partial v}{\partial y}=0, \\
u \frac{\partial u}{\partial x}+v \frac{\partial u}{\partial y}=-\frac{1}{\rho_{n f}} \frac{\partial p}{\partial x}+\frac{\mu_{n f}}{\rho_{n f}} \frac{\partial^{2} u}{\partial y^{2}}, \\
u \frac{\partial v}{\partial x}+v \frac{\partial v}{\partial y}=-\frac{1}{\rho_{n f}} \frac{\partial p}{\partial y}+\frac{\mu_{n f}}{\rho_{n f}} \frac{\partial^{2} v}{\partial y^{2}}, \\
u \frac{\partial T}{\partial x}+v \frac{\partial T}{\partial y}=\alpha_{n f} \frac{\partial^{2} T}{\partial y^{2}} .
\end{gathered}
$$

Following Khanafer et al. [11] and Oztop and Abu-Nada [12] we employ

$$
\begin{gathered}
\mu_{n f}=\frac{\mu_{f}}{(1-\phi)^{2.5}}, \quad \alpha_{n f}=\frac{k_{n f}}{\left(\rho C_{p}\right)_{n f}}, \\
\rho_{n f}=(1-\phi) \rho_{f}+\phi \rho_{s}, \\
\left(\rho C_{p}\right)_{n f}=(1-\phi)\left(\rho C_{p}\right)_{f}+\phi\left(\rho C_{p}\right)_{s}, \\
\frac{k_{n f}}{k_{f}}=\frac{\left(k_{s}+2 k_{f}\right)-2 \phi\left(k_{f}-k_{s}\right)}{\left(k_{s}+2 k_{f}\right)+\phi\left(k_{f}-k_{s}\right)},
\end{gathered}
$$

where $\left(\rho C_{p}\right)_{n f}$ is the heat capacity of the nanofluid. The dynamic viscosity of the base fluid $\mu_{f}$ has been proposed by Brinkman [13]. Strictly expressions (5) are restricted to spherical (or near spherical) nanoparticles. The boundary conditions of Eqs. (1)-(4) are

$$
\begin{gathered}
u=u_{w}(x)=b(x+c), v=0, T=T_{w} \quad \text { at } \quad y=0, \\
u=u_{e} \rightarrow a x, \quad T \rightarrow T_{\infty} \text { as } y \rightarrow \infty .
\end{gathered}
$$

Following Wang [3], we presume that Eqs. (1)-(4) subject to the boundary conditions (6) admit the similarity solution

$$
\begin{aligned}
& \eta=\left(\frac{a}{\nu_{f}}\right)^{1 / 2} y, \quad u=a x f^{\prime}(\eta)+b c g(\eta), \\
& v=-\left(a \nu_{f}\right)^{1 / 2} f(\eta), \quad \theta(\eta)=\frac{T-T_{\infty}}{T_{w}-T_{\infty}},
\end{aligned}
$$

where primes denote differentiation with respect to $\eta$. Using Eq. (3) and the boundary conditions (6), we acquire the following expression for the pressure $p$

$$
p=p_{0}-p_{n f} \frac{a^{2} x^{2}}{2}-\mu_{n f} \frac{v^{2}}{2}+\mu_{n f} \frac{d v}{d y},
$$

where $p_{0}$ is the stagnation pressure. Thus, we have

$$
-\frac{1}{\rho_{n f}} \frac{\partial p}{\partial x}=\frac{\partial u_{e}}{\partial t}+\frac{\partial u_{e}}{\partial x} \quad \text { as } \quad y \rightarrow \infty .
$$

Subtituting Eqs. (7) and (9) into Eqs. (2)-(4), the following ordinary differential equations are obtained

$$
\begin{gathered}
A f^{\prime \prime \prime}+f f^{\prime \prime}-f^{\prime 2}+1=0, \\
A g^{\prime \prime}+f g^{\prime}-f^{\prime} g=0, \\
B \frac{1}{P r} \theta^{\prime \prime}+f \theta^{\prime}=0,
\end{gathered}
$$

where

$$
\begin{aligned}
A & =\frac{1}{(1-\phi)^{2.5}\left(1-\phi+\phi \rho_{s} / \rho_{f}\right)}, \\
B & =\frac{k_{n f} / k_{f}}{\left[1-\phi+\phi\left(\rho C_{p}\right)_{s} /\left(\rho C_{p}\right)_{f}\right]},
\end{aligned}
$$

subject to the new boundary conditions

$$
\begin{gathered}
f(0)=0, \quad f^{\prime}(0)=\epsilon, \quad g(0)=1, \quad \theta(0)=1 \\
f^{\prime}(\infty) \rightarrow 1, \quad g(\infty) \rightarrow 0, \quad \theta(\infty) \rightarrow 0 .
\end{gathered}
$$

In the above equations, $\operatorname{Pr}$ is the Prandtl number and $\epsilon$ is the velocity ratio parameter defined as

$$
\epsilon=\frac{b}{a},
$$

where $\epsilon>0$ for stretching case and $\epsilon<0$ for shrinking case.

The physical quantities of interest are represented as the skin friction coefficient $C_{f}$ and the local Nusselt number $N u_{x}$, which defined as

$$
C_{f}=\frac{\tau_{w}}{\rho_{f} u_{e}^{2}}, \quad N u_{x}=\frac{x q_{w}}{k_{f}\left(T_{w}-T_{\infty}\right)},
$$

where $\tau_{w}$ is the surface shear stress and $q_{w}$ is the surface heat flux derived from

$$
\tau_{w}=\mu_{n f}\left(\frac{\partial u}{\partial y}\right)_{y=0}, \quad q_{w}=k_{n f}\left(\frac{\partial T}{\partial y}\right)_{y=0} .
$$

Using the similarity variables (7), we obtain

$$
\begin{gathered}
C_{f} R e_{x}^{1 / 2}=\frac{1}{(1-\phi)^{2.5}}\left[f^{\prime \prime}(0)+\frac{b c}{a x} g^{\prime}(0)\right], \\
N u_{x} R e_{x}^{-1 / 2}=-\frac{k_{n f}}{k_{f}} \theta^{\prime}(0),
\end{gathered}
$$

where the local Reynolds number is represented as $R e_{x}=$ $\frac{u_{e} x}{\nu_{f}}$.

\section{Stability Analysis}

To carry out the stability analysis, following Merkin [5] and Weidman et al. [6], we take the problem in unsteady case into account. The continuity Eq. (1) holds, while Eqs. (2)-(4) are replaced by

$$
\begin{gathered}
\frac{\partial u}{\partial t}+u \frac{\partial u}{\partial x}+v \frac{\partial u}{\partial y}=-\frac{1}{\rho_{n f}} \frac{\partial p}{\partial x}+\frac{\mu_{n f}}{\rho_{n f}} \frac{\partial^{2} u}{\partial y^{2}} \\
\frac{\partial v}{\partial t}+u \frac{\partial v}{\partial x}+v \frac{\partial v}{\partial y}=-\frac{1}{\rho_{n f}} \frac{\partial p}{\partial y}+\frac{\mu_{n f}}{\rho_{n f}} \frac{\partial^{2} v}{\partial y^{2}} \\
\frac{\partial T}{\partial t}+u \frac{\partial T}{\partial x}+v \frac{\partial T}{\partial y}=\alpha_{n f} \frac{\partial^{2} T}{\partial y^{2}}
\end{gathered}
$$


where $t$ denotes the time. We are now introducing the following new dimensionless variables:

$$
\begin{gathered}
\eta=\left(\frac{a}{\nu_{f}}\right)^{1 / 2} y, \quad \tau=a t \\
u=a x \frac{\partial f}{\partial \eta}(\eta, \tau)+b c g(\eta, \tau) \\
v=-\left(a \nu_{f}\right)^{1 / 2} f(\eta, \tau), \quad \theta(\eta, \tau)=\frac{T-T_{\infty}}{T_{w}-T_{\infty}}
\end{gathered}
$$

so that Eqs. (20)-(22) can be expressed as

$$
\begin{gathered}
A \frac{\partial^{3} f}{\partial \eta^{3}}-\left(\frac{\partial f}{\partial \eta}\right)^{2}+f \frac{\partial^{2} f}{\partial \eta^{2}}+1-\frac{\partial^{2} f}{\partial \eta \partial \tau}=0 \\
A \frac{\partial^{2} g}{\partial \eta^{2}}-f \frac{\partial g}{\partial \eta}-g \frac{\partial f}{\partial \eta}-\frac{\partial g}{\partial \tau}=0 \\
B \frac{1}{P r} \frac{\partial^{2} \theta}{\partial \eta^{2}}+f \frac{\partial \theta}{\partial \eta}-\frac{\partial \theta}{\partial \tau}=0
\end{gathered}
$$

and can be remotely subjected to the boundary conditions

$$
\begin{aligned}
& f(0, \tau)=0, \frac{\partial f}{\partial \eta}(0, \tau)=\epsilon, g(0, \tau)=1, \theta(0, \tau)=1 \\
& \frac{\partial f}{\partial \eta}(\eta, \tau) \rightarrow 1, g(\eta, \tau) \rightarrow 0, \theta(\eta, \tau) \rightarrow 0 \text { as } \eta \rightarrow \infty
\end{aligned}
$$

To put the stability of the steady flow solution into a test, $f(\eta)=f_{0}(\eta), g(\eta)=g_{0}(\eta)$ and $\theta(\eta)=\theta_{0}(\eta)$ satisfying the boundary value problem (10)-(13), we set down

$$
\begin{aligned}
& f(\eta, \tau)=f_{0}(\eta)+e^{-\gamma \tau} F(\eta, \tau), \\
& g(\eta, \tau)=g_{0}(\eta)+e^{-\gamma \tau} G(\eta, \tau), \\
& \theta(\eta, \tau)=\theta_{0}(\eta)+e^{-\gamma \tau} T(\eta, \tau),
\end{aligned}
$$

where $\gamma$ represents an unknown eigenvalue, $F(\eta, \tau), G(\eta, \tau)$ and $T(\eta, \tau)$ are small relative to $f_{0}(\eta), g_{0}(\eta)$ and $\theta_{0}(\eta)$. Solutions of the eigenvalue problem in Eqs. (22)-(25) give an infinite set of eigenvalue problem $\gamma_{1}<\gamma_{2}<\ldots$; if $\gamma_{1}$ is negative, there is an initial growth of disturbances and the flow is deemed to be unstable but when $\gamma_{1}$ is positive, is an initial decay of disturbances and the flow is believe to be stable. Introducing (28) into Eqs. (24)-(27), we get the following linearized problem

$$
\begin{gathered}
A \frac{\partial^{3} F}{\partial \eta^{3}}+f_{0} \frac{\partial^{2} F}{\partial \eta^{2}}+f_{0}^{\prime \prime} F-\left(2 f_{0}^{\prime}-\gamma\right) \frac{\partial F}{\partial \eta}-\frac{\partial^{2} F}{\partial \eta \partial \tau}=0 \\
A \frac{\partial^{2} G}{\partial \eta^{2}}-f_{0} \frac{\partial G}{\partial \eta}-g_{0}^{\prime} F-\left(f_{0}^{\prime}-\gamma\right) G-g_{0} \frac{\partial F}{\partial \eta}-\frac{\partial G}{\partial \tau}=0 \\
B \frac{\partial^{2} T}{\partial \eta^{2}}+f_{0} \frac{\partial T}{\partial \eta}+\theta_{0}^{\prime} F+\gamma T-\frac{\partial T}{\partial \tau}=0
\end{gathered}
$$

and are subjected to the boundary conditions

$$
\begin{aligned}
& F(0, \tau)=0, \frac{\partial F}{\partial \eta}(0, \tau)=0, G(0, \tau)=1, T(0, \tau)=1 \\
& \frac{\partial F}{\partial \eta}(\eta, \tau) \rightarrow 0, G(\eta, \tau) \rightarrow 0, T(\eta, \tau) \rightarrow 0 \text { as } \eta \rightarrow \infty
\end{aligned}
$$

The solutions $f(\eta)=f_{0}(\eta), g(\eta)=g_{0}(\eta)$ and $\theta(\eta)=$ $\theta_{0}(\eta)$ of the steady Eqs. (10)-(14) are gained by setting $\tau=0$. Hence $F(\eta)=F_{0}(\eta), G(\eta)=G_{0}(\eta)$ and $T(\eta)=T_{0}(\eta)$ in Eqs. (29)-(32) identify initial growth or decay of the solution (28). In this respect, linear eigenvalue problem needs to be solved

$$
\begin{gathered}
A F_{0}^{\prime \prime \prime}+f_{0}^{\prime \prime} F_{0}+f_{0} F_{0}^{\prime \prime}-\left(2 f_{0}^{\prime}-\gamma\right) F_{0}^{\prime}=0, \\
A G_{0}^{\prime \prime}-f_{0} G_{0}^{\prime}-F_{0} g_{0}^{\prime}-f_{0}^{\prime} G_{0}-F_{0}^{\prime} g_{0}+\gamma G_{0}=0, \\
B \frac{1}{P r} T_{0}^{\prime \prime}+f_{0} T_{0}^{\prime}+\theta_{0}^{\prime} F_{0}+\gamma T_{0}=0,
\end{gathered}
$$

along with the boundary conditions

$$
\begin{gathered}
F_{0}(0)=0, \quad F_{0}^{\prime}(0)=0, \quad G_{0}(0)=0, \quad T_{0}(0)=0 \\
F_{0}^{\prime}(\eta) \rightarrow 0, \quad G_{0}(\eta) \rightarrow 0, \quad T_{0}(\eta) \rightarrow 0 \quad \text { as } \quad \eta \rightarrow \infty
\end{gathered}
$$

The stability of the steady-state flow solution is based on the smallest eigenvalue $\gamma_{1}$. Therefore, the condition $F_{0}^{\prime}(\eta) \rightarrow 0$ as $\eta \rightarrow \infty$ has been put at rest as suggested by Harris et al. [14] and for a fixed value of eigenvalue, $\gamma$. Eqs. (33)-(35) will be solved with the introduction of a new boundary condition that is $F_{0}^{\prime \prime}(\eta)=1$.

\section{Results and Discussion}

The governing ordinary differential equations (10)-(12), subject to the boundary conditions (14) have been solved numerically using bvp4c function in Matlab. The effects of the solid volume fraction of nanofluid $\phi$ and the Prandtl number $\mathrm{Pr}$ are examined for three differents nanofluid which are copper $\mathrm{Cu}$-water, alumina $\mathrm{Al}_{2} \mathrm{O}_{3}$-water and titania $\mathrm{TiO}_{2}$-water as working fluids. Following Oztop and Abu-Nada [12], the chosen value of the Prandtl number $\operatorname{Pr}$ is 6.2 (water) and the value of nanoparticle is from 0 to $0.2(0 \leq \phi \leq 0.2)$ in which $\phi=0$ must be compatible with regular fluid. The thermophysical properties of the base fluid and nanofluid are stated in Table 1.

Table 1. Thermophysical properties of the base fluid and nanoparticles (Oztop and Abu-Nada [12])

\begin{tabular}{ccccc}
\hline $\begin{array}{c}\text { Physical } \\
\text { Properties }\end{array}$ & $\begin{array}{c}\text { Fluid Phase } \\
\text { (water) }\end{array}$ & $\mathrm{Cu}$ & $\mathrm{Al}_{2} \mathrm{O}_{3}$ & $\mathrm{TiO}_{2}$ \\
\hline$C_{p}(\mathrm{~J} / \mathrm{kgK})$ & 4179 & 385 & 765 & 686.2 \\
$\rho\left(\mathrm{kg} / \mathrm{m}^{2}\right)$ & 997.1 & 8933 & 3970 & 4250 \\
$k(W / m K)$ & 0.613 & 400 & 40 & 8.9538 \\
\hline
\end{tabular}

All the profiles presented in the form of figures satisfy the boundary condition (14) and produce asymptotic graph. A comparison result for some values of $f^{\prime \prime}(0)$ has been made with previous study with those of Wang[3] and Bachok et al.[15] in order to validate this study. This comparison data is presented in Table 2 and it shows a favorable agreements. Therefore, we are confident that the numerical results obtained in this study are accurate. Figures 1-3 displays the effect of different nanoparticles on $f^{\prime}(\eta), g(\eta)$ and $\theta(\eta)$ profiles. It is clearly shown that the existence of dual solutions in this study. 
Table 2. Values of the skin friction coefficient $f^{\prime \prime}(0)$ for some value of $\epsilon$ and $\phi$ for $C u$ - water working fluid

\begin{tabular}{|c|c|c|c|c|c|c|c|}
\hline \multirow{2}{*}{$\epsilon$} & Wang[3] & \multicolumn{3}{|c|}{ Bachok et al.[15] } & \multicolumn{3}{|c|}{ Present } \\
\hline & $\phi=0$ & $\phi=0$ & $\phi=0.1$ & $\phi=0.2$ & $\phi=0$ & $\phi=0.1$ & $\phi=0.2$ \\
\hline 2 & -1.88731 & -1.887307 & -2.217106 & -2.298822 & -1.887307 & -2.217106 & -2.298822 \\
\hline 1 & 0 & 0 & 0 & 0 & 0 & 0 & 0 \\
\hline 0.5 & 0.71330 & 0.713295 & 0.837940 & 0.868824 & 0.713295 & 0.837940 & 0.868824 \\
\hline 0 & 1.232588 & 1.232588 & 1.447977 & 1.501346 & 1.232588 & 1.447977 & 1.501346 \\
\hline-0.5 & 1.49567 & 1.495670 & 1.757032 & 1.821791 & 1.495669 & 1.757032 & 1.821791 \\
\hline-1 & $\begin{array}{c}1.32882 \\
{[0]}\end{array}$ & $\begin{array}{c}1.328817 \\
{[0]}\end{array}$ & $\begin{array}{c}1.561022 \\
{[0]}\end{array}$ & $\begin{array}{c}1.618557 \\
{[0]}\end{array}$ & $\begin{array}{c}1.328817 \\
{[0]}\end{array}$ & $\begin{array}{c}1.561022 \\
{[0]}\end{array}$ & $\begin{array}{c}1.618557 \\
{[0]}\end{array}$ \\
\hline-1.15 & $\begin{array}{c}1.082231 \\
{[0.116702]}\end{array}$ & $\begin{array}{c}1.082231 \\
{[0.116702]}\end{array}$ & $\begin{array}{c}1.271347 \\
{[0.137095]}\end{array}$ & $\begin{array}{c}1.318205 \\
{[0.142148]}\end{array}$ & $\begin{array}{c}1.082231 \\
{[0.116701]}\end{array}$ & $\begin{array}{c}1.271347 \\
{[0.137095]}\end{array}$ & $\begin{array}{c}1.318205 \\
{[0.142148]}\end{array}$ \\
\hline-1.2 & & $\begin{array}{c}0.932473 \\
{[0.233650]}\end{array}$ & $\begin{array}{c}1.095419 \\
{[0.274479]}\end{array}$ & $\begin{array}{c}1.135794 \\
{[0.284596]}\end{array}$ & $\begin{array}{c}0.932473 \\
{[0.233649]}\end{array}$ & $\begin{array}{c}1.095419 \\
{[0.274479]}\end{array}$ & $\begin{array}{c}1.135793 \\
{[0.284596]}\end{array}$ \\
\hline 1.2465 & 0.55430 & $\begin{array}{c}0.584281 \\
{[0.554297]}\end{array}$ & $\begin{array}{c}0.686379 \\
{[0.651161]}\end{array}$ & $\begin{array}{c}0.711679 \\
{[0.675159]}\end{array}$ & $\begin{array}{c}0.584282 \\
{[0.554295]}\end{array}$ & $\begin{array}{c}0.686382 \\
{[0.651157]}\end{array}$ & $\begin{array}{r}0.711680 \\
{[0.675157]}\end{array}$ \\
\hline
\end{tabular}

[ ] indicate second solution.

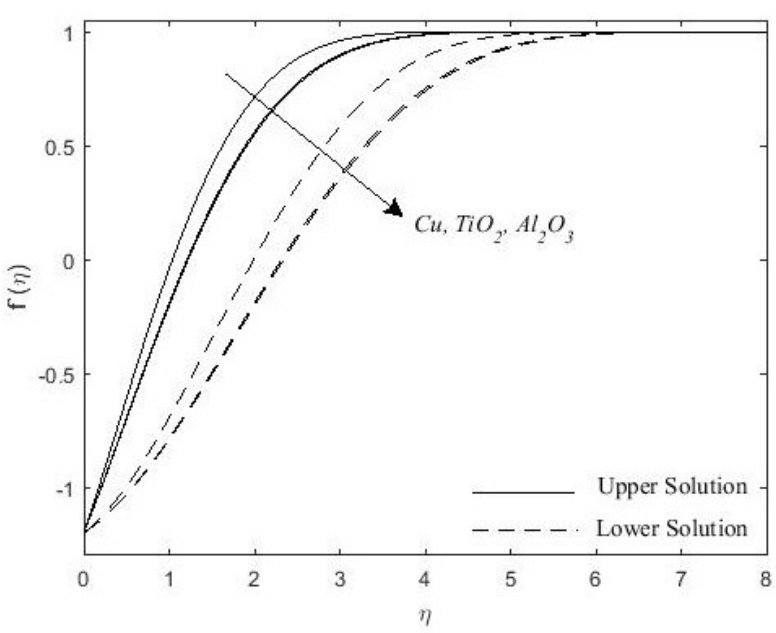

Figure 1. Velocity profile for various nanoparticles

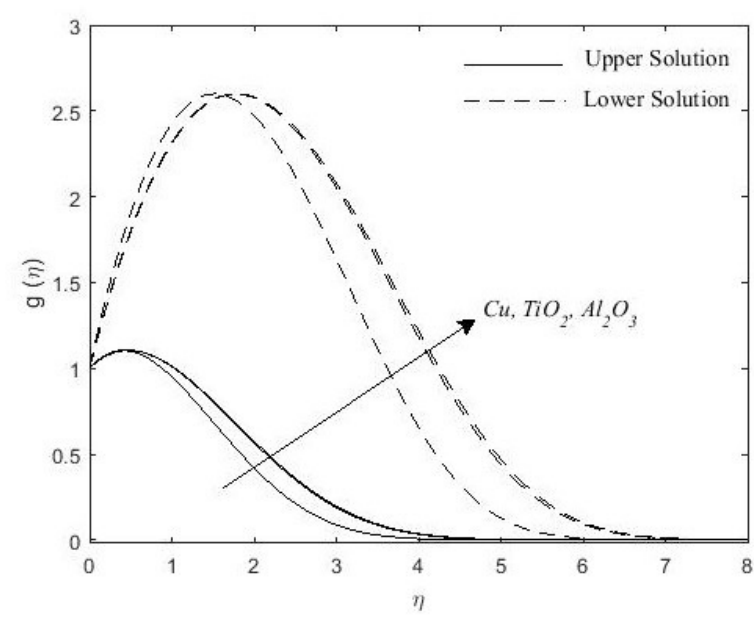

Figure 2. Velocity $g$ profile for various nanoparticles

The variation of $f^{\prime \prime}(0), g^{\prime}(0)$ and $-\theta^{\prime}(0)$ are illustrated in Figures 4-9 for different nanoparticles $\left(\mathrm{Cu}, \mathrm{Al}_{2} \mathrm{O}_{3}, \mathrm{TiO}_{2}\right)$ and nanoparticle volume fraction $\phi$ with stretching/shrinking

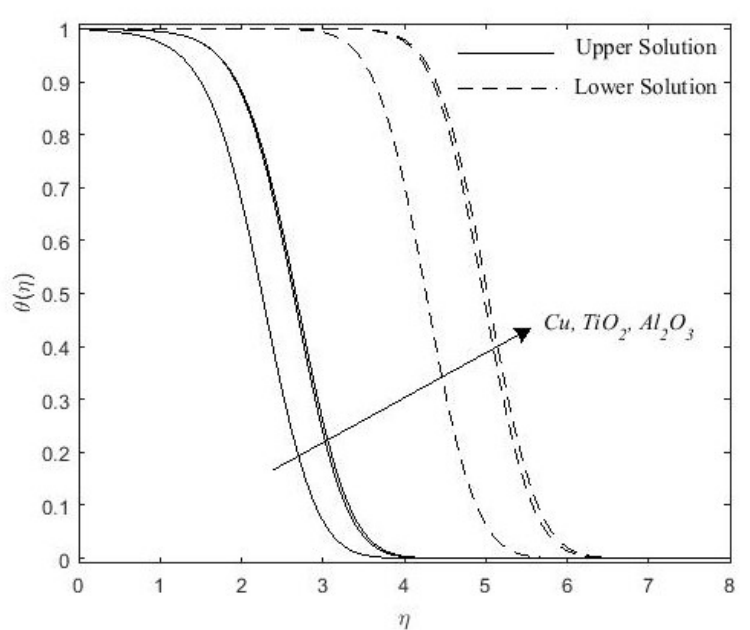

Figure 3. Temperature profile for various nanoparticles

parameter $\epsilon$. Based on these figures, for the value $\epsilon>-1$ the solutions are unique, dual solutions exist when the value $-1.2465 \leq \epsilon \leq-1$ and no solution exist when $\epsilon<$ $-1.2465=\epsilon_{c}$, where $\epsilon_{c}$ is the critical point. This similar critical point value is also reported by Noor et al. [16] and Awaludin et al. [17]. Notice that from Figures 4 and 7, the value of $f^{\prime \prime}(0)$ is zero when $\epsilon=1$. This due to the fact that when the fluid and solid boundary move with the equal velocity, there is no friction detected on the fluid-solid interface. The skin friction $f^{\prime \prime}(0)$ and Nusselt number $-\theta^{\prime}(0)$ have higher value for $\mathrm{Cu}$ than for $\mathrm{Al}_{2} \mathrm{O}_{3}$ and $\mathrm{TiO}_{2}$ as shown in Figures 4 and 6 respectively. This is due to the physical properties of fluid and nanoparticles where the thermal conductivity of $\mathrm{Cu}$ is much greater compared to $\mathrm{Al}_{2} \mathrm{O}_{3}$ and $\mathrm{TiO}_{2}$.

Based on all these figures, the existence of non-unique solution (dual solutions) are clearly shown. To determine which dual solutions are stable and physically realizable in practice, and which are not, we tested these features by considering the stability of these solutions. Therefore, the eigenvalue problem (33)-(36) is solved for the smallest eigenvalues $\gamma$ on the upper and lower solution branches. These results are presented in 


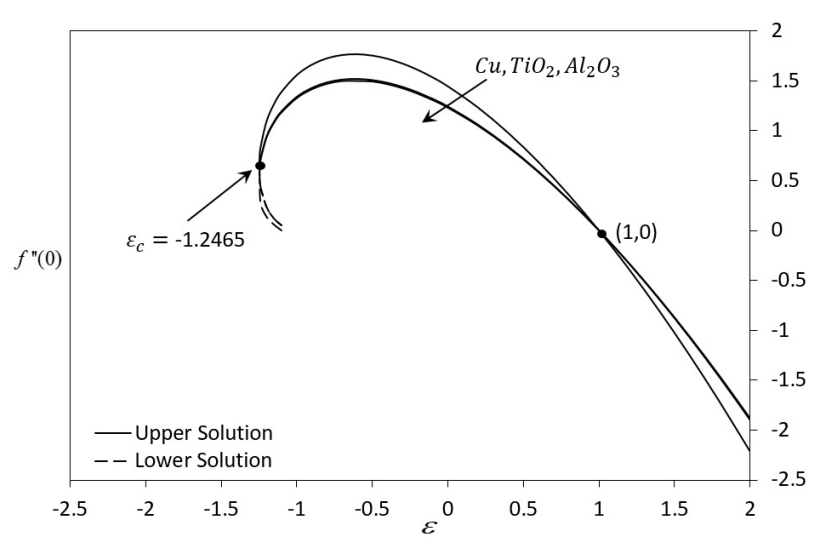

Figure 4. Variation of skin friction coefficient for various nanoparticles

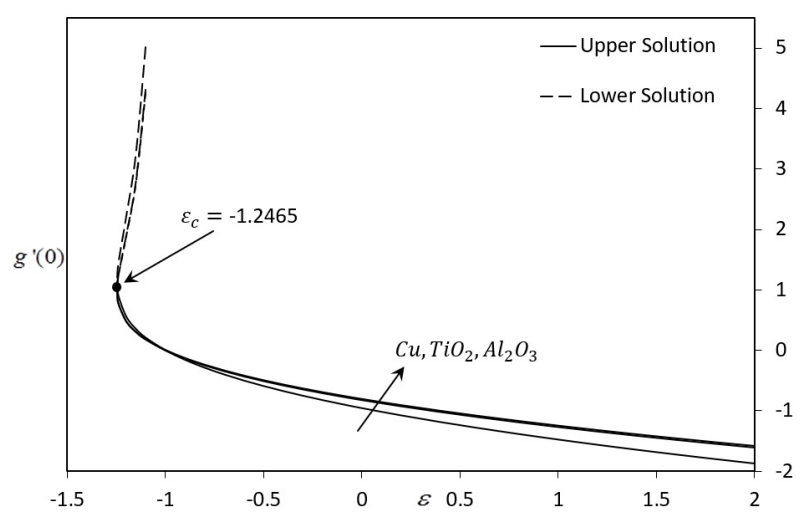

Figure 5. Variation of $g^{\prime}(0)$ for various nanoparticles

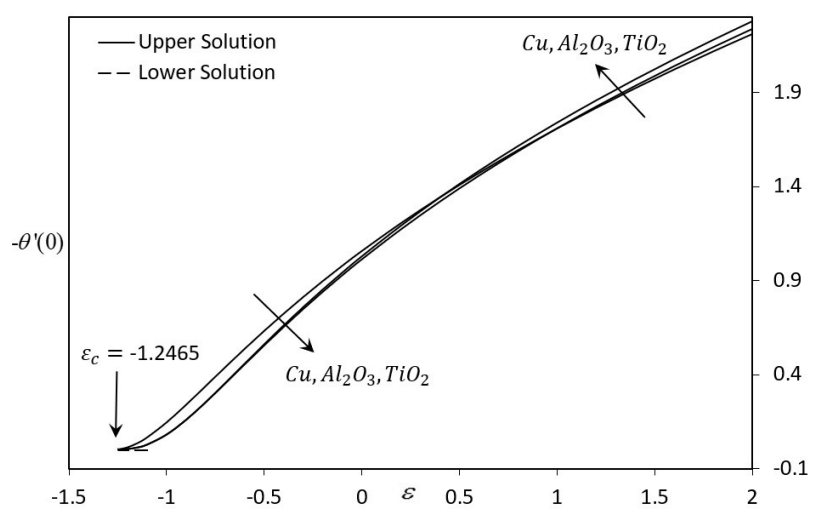

Figure 6. Variation of local Nusselt number for various nanoparticles

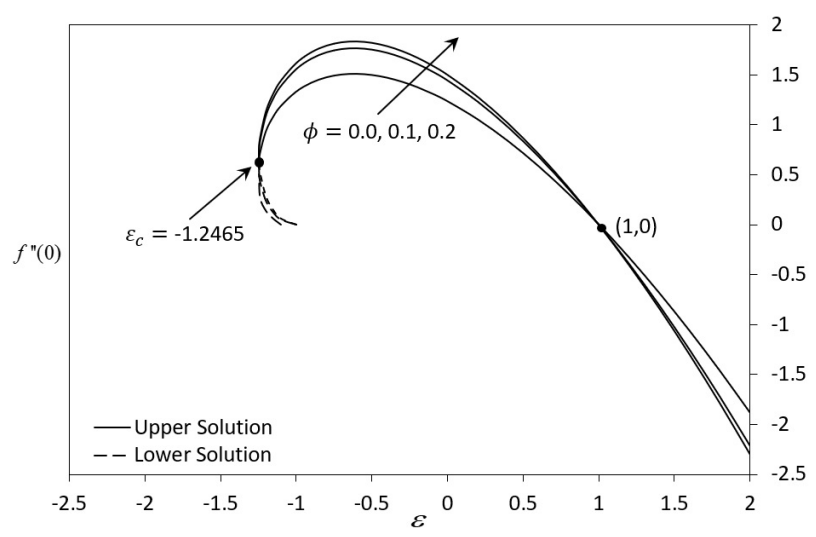

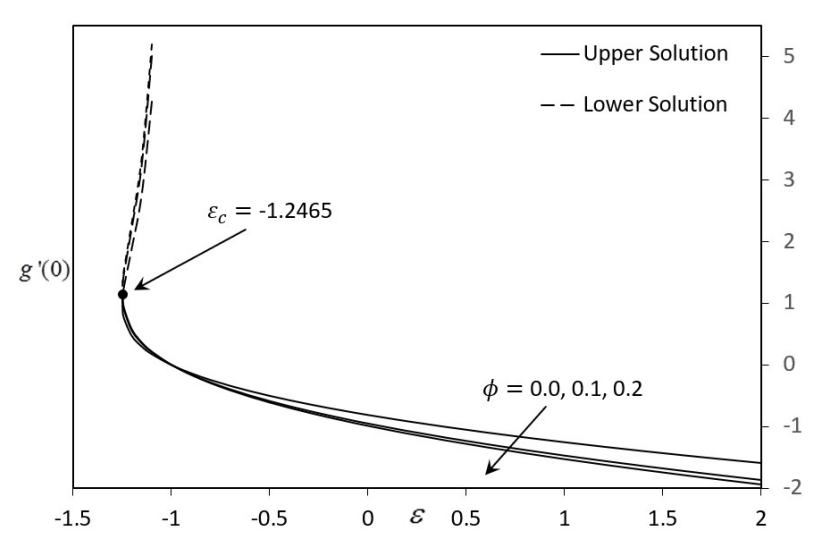

Figure 8. Variation of $g^{\prime}(0)$ for various value of $\phi$

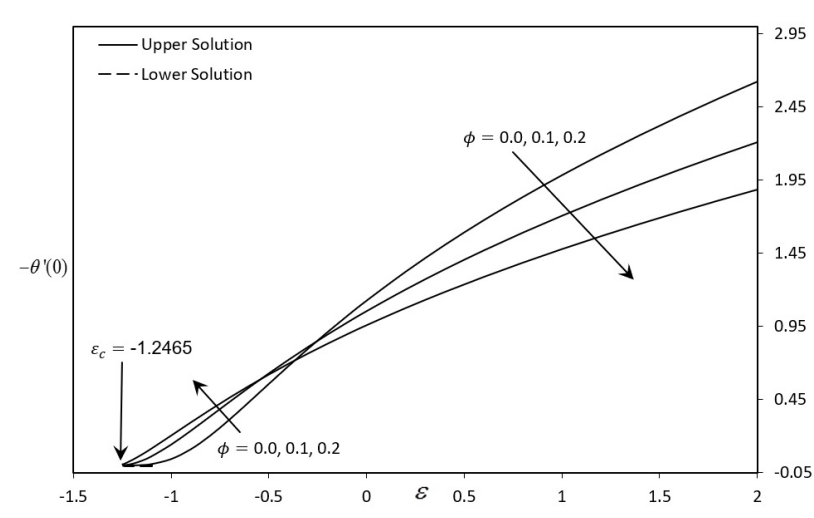

Figure 9. Variation of local Nusselt number for various value of $\phi$

Table 3 for several values of $\epsilon$ when $\operatorname{Pr}=6.2$ and $\phi=0.2$. From the table, it noticed that the smallest eigenvalue $\gamma_{1}$ gives a positive value for the first solution and negative value for the second solution. Positive value indicate that is an initial decay of disturbance for the first solution, while the negative value for the second solution showed an initial growth of disturbance. Hence, we can draw a conclusion that only the upper branch solutions are physically significant while the lower branch solutions are not. Moreover, it is important to note the eigen values for all nanoparticles $\mathrm{Cu}, \mathrm{Al}_{2} \mathrm{O}_{3}$ and $\mathrm{TiO}_{2}$ are the same for the fixed value of $\epsilon$.

Table 3. Smallest eigenvalues $\gamma$ for different nanofluid with several values of $\epsilon$ when $\operatorname{Pr}=6.2$ and $\phi=0.2$

\begin{tabular}{cccc}
\hline Nanofluid & $\epsilon$ & First Solution & Second Solution \\
\hline \multirow{2}{*}{$\mathrm{Cu}$} & -1.2 & 0.57796 & -0.51721 \\
& -1.24 & 0.21205 & -0.20364 \\
& -1.246 & 0.06216 & -0.06142 \\
\hline \multirow{2}{*}{$\mathrm{Al}_{2} \mathrm{O}_{3}$} & -1.2 & 0.57796 & -0.51721 \\
& -1.24 & 0.21205 & -0.20364 \\
& -1.246 & 0.06216 & -0.06142 \\
\hline \multirow{2}{*}{$\mathrm{TiO}_{2}$} & -1.2 & 0.57796 & -0.51721 \\
& -1.24 & 0.21205 & -0.20364 \\
& -1.246 & 0.06216 & -0.06142 \\
\hline
\end{tabular}

Figure 7. Variation of skin friction coefficient for various value of $\phi$ 


\section{Conclusions}

A numerical study is performed for the problem of the flow and heat transfer characteristics of a nanofluids $\left(\mathrm{Cu}, \mathrm{Al}_{2} \mathrm{O}_{3}, \mathrm{TiO}_{2}\right)$ over a stretching or shrinking sheet in its own plane. Dual solutions are found to be exist for certain ranges values of stretching/shrinking parameter $\left(\epsilon_{c}<\epsilon<\right.$ $-1)$. The stability analysis is done via bvp4c function in MATLAB software and their results found that the first solution (upper branch) is stable and valid physically, while the second solution (lower branch) is unstable.

\section{Acknowledgements}

The authors gratefully acknowledge the financial received in the form Geran Putra IPS (Project number: GPIPS/2018/9570000) from the Universiti Putra Malaysia and $\mathrm{MyPhD}$ from the Ministry of Higher Education, Malaysia.

\section{Nomenclature}

\section{Roman Letters}

a positive constant variable

$b \quad$ stretching/shrinking rate variable

$c \quad$ stretching origin

$C_{f} \quad$ skin friction coefficient

$C_{p} \quad$ specific heat capacity

$f(\eta)$ dimensionless stream function

$g(\eta)$ dimensionless stream function

$k$ thermal conductivity

$N u_{x} \quad$ local Nusselt number

$p \quad$ pressure

$p_{0} \quad$ stagnation pressure

$\mathrm{Pr} \quad$ Prandtl number

$q_{w} \quad$ surface heat flux

$R e_{x} \quad$ local Reynolds number

$t$ time

$T \quad$ temperature of the nanofluid

$u_{e} \quad$ velocity at the edge of the boundary layer

$u, v \quad$ velocity components along the $x$ and $y$ directions, respectively

$x, y \quad$ Cartesian coordinates

\section{Greek Symbols}

$\alpha \quad$ thermal diffusivity of the nanofluid

$\gamma \quad$ eigenvalue

$\gamma_{1} \quad$ smallest eigenvalue

$\epsilon \quad$ stretching/shrinking parameter

$\eta \quad$ similarity variable

$\theta(\eta) \quad$ dimensionless temperature

$\mu$ dynamic viscosity

$\nu \quad$ kinematic viscosity

$\rho$ density

$\tau \quad$ dimensionless time

$\tau_{w} \quad$ surface shear stress

$\phi \quad$ nanoparticle volume fraction

\section{Subscripts}

$w \quad$ condition at the surface

$\infty \quad$ condition outside of boundary layer

c critical value

$f \quad$ base fluid

nf nanofluid

$s \quad$ solid fraction

\section{Superscripts}

differentiation with respect to $\eta$

\section{REFERENCES}

[1] K. Hiemenz. Die grenzschicht an einem in den gleichformigen flussigkeitsstrom eingetauchten geraden kreiszylinder. Dingler's Polytech J, 326(9), 321-324, 1911.

[2] M. Miklavcic, C. Y. Wang. Viscous flow due to a shrinking shee, Quarterly of Applied Mathematics, 64(2), 283-290, 2006.

[3] C. Y. Wang. Stagnation flow towards a shrinking sheet, International Journal of Non-Linear Mechanics, 43(9), 377-382, 2008.

[4] F. M. Ali, R. Nazar, N. M. Arifin, I. Pop. Numerical solutions of Wang's stretching/shrinking sheet problem for nanofluids, AIP Conference Proceedings, 1557, 330-334, 2013.

[5] J. H. Merkin. On dual solutions occuring in mixed convection in a porous medium, Journal of Engineering Mathematics, 20, 171-179, 1985.

[6] P. D. Weidman, D. G. Kubitschek, A. M. J. Davis. The effect of transpiration on self-similar boundary layer flow over moving surfaces, International Journal of Engineering Sciences, 44, 730-737, 2006.

[7] S. Mansur, A. Ishak, I. Pop. The magnetohydrodynamic stagnation point flow of a nanofluid over a stretching/shrinking sheet with suction, PLOS ONE, Vol.10, No.3, 1-14, 2015.

[8] N. S. M. Adnan, N. M. Arifin. Stability analysis of boundary layer flow and heat transfer over a permeable exponentially shrinking sheet in the presence of thermal radiation and partial slip, Journal of Physics: Conference Series, 890, 012046, 2017.

[9] M. M. Junoh, F. M. Ali, I. Pop. MHD stagnation-point flow of a nanofluid past a stretching/shrinking sheet with induced magnetic field, Journal of Engineering and Applied Sciences 13, 10474-10481, 2018.

[10] R. K. Tiwari, M. K. Das. Heat transfer augmentation in a two-sided liddriven differentially heated square cavity utilizing nanofluids, International Journal of Heat and Mass Transfer, 50, 2002-2018, 2007.

[11] K. Khanafer, K. Vafai, M. Lightstone. Buoyancy-driven heat transfer enhancement in a two-dimensional enclosure utilizing nanofluids, International Journal of Heat and Mass Transfer, 46, 3639-3653, 2003. 
[12] H. F. Oztop, E. Abu-Nada. Numerical study of natural convection in partially heated rectangular enclosures filled with nanofluids, International Journal of Heat and Fluid Flow, 29, 1326-1336, 2008.

[13] H. C. Brinkman. The viscosity of concentrated suspensions and solution, Journal of Chemical Physics, 20, 571-581, 1952.

[14] S. D. Harris, D. B. Ingham, I. Pop. Mixed convection boundarylayer flow near the stagnation point on a vertical surface in a porous medium: Brinkman model with slip, Transport in Porous Media, 77, 267-285, 2009.
[15] N. Bachok, A. Ishak, I. Pop. Stagnation-point flow over a stretching/shrinking sheet in a nanofluid, Nanoscale Research Letters, 6, 623-632, 2011.

[16] M. A. M. Noor, R. Nazar, K. Jafar. Stability analysis of stagnation-point flow past a shrinking sheet in a nanofluid, Journal of Quality Measurement and Analysis, 10, 51-63, 2014.

[17] I. S. Awaludin, P. D. Weidman, A. Ishak. Stability analysis of stagnation-point flow over a stretching/shrinking sheet, AIP Advances, 6, 045308, 2016. 